\title{
Fetus inside Brain - Mature Cystic Teratoma in Posterior Fossa
}

\author{
Farid Yudoyono, Mirna Sobana, Agung Budi Sutiono, Muhammad Zafrullah Arifin \\ Department of Neurosurgery, Faculty of Medicine, Universitas Padjadjaran-Dr. Hasan Sadikin \\ General Hospital
}

\begin{tabular}{|c|c|}
\hline \multirow[t]{3}{*}{ Abstract } & $\begin{array}{l}\text { Objective: To describe a rare case of posterior fossa cystic teratoma in central } \\
\text { nervous system. }\end{array}$ \\
\hline & $\begin{array}{l}\text { Methods: A 2-year old boy was admitted with a chief complaint of decreased } \\
\text { consciousness with tonic clonic seizure. Non-Contrast Head Computed } \\
\text { Tomography (NCCT) scan showed acute hydrocephalus and a well-defined } \\
\text { extra-axial cystic lesion mass, } 3.4 \times 3.9 \times 4.2 \mathrm{~cm} \text { in size, in the posterior } \\
\text { fossa. }\end{array}$ \\
\hline & $\begin{array}{l}\text { Results: Patient underwent a total resection of the tumor. No systemic } \\
\text { complication was found in ten days following the surgery. There was no } \\
\text { evidence of tumor recurrence one year after the surgery. Thehistopathologycal } \\
\text { diagnosis of the tumor was cystic teratoma. }\end{array}$ \\
\hline $\begin{array}{l}\text { Received: } \\
\text { July } 9,2015\end{array}$ & $\begin{array}{l}\text { Conclusions: Mature cyst teratoma located in the posterior fossa is a rare } \\
\text { case. Total resection and long-term follow up is the treatment of choice for }\end{array}$ \\
\hline \multirow{2}{*}{$\begin{array}{l}\text { Revised: } \\
\text { October } 27,2015\end{array}$} & mature teratoma. \\
\hline & Keywords: Hydrocephalus, posterior fossa, teratoma \\
\hline $\begin{array}{l}\text { Accepted: } \\
\text { February } 26,2016\end{array}$ & IJIHS. 2016;4(1):43-6 \\
\hline
\end{tabular}

\section{Introduction}

Meckel first reported a rare case of fetus-infetu in the $18^{\text {th }}$ century, mostly presented in the sacrum, scrotum, mouth, liver, and cranium. ${ }^{1}$ Accounting for $0.5-5 \%$ of all intracranial tumors, intracranial teratoma represents a rare lesion with two peaks distribution before 5 years of age $(10 \%)$ and between 5 and 14 years of age (48\%) with males more affected than females. ${ }^{2-5,10}$ About $54 \%$ to $70 \%$ of all childhood brain tumors originated from the posterior fossa are cystic mass. Therefore, a teratoma located in the posterior fossa is uncommon. Although most of intracranial teratomas are located in the midline structures, particularly the pineal, corpus callosum and suprasellar regions, teratomas can also be identified outside the midline regions, including in the cerebellar hemisphere, basal ganglia, lateral ventricle,

\footnotetext{
Correspondence:

Farid Yudoyono, Department of Neurosurgery, Faculty of Medicine, Universitas Padjadjaran-Dr. Hasan Sadikin General Hospital

Jl. Pasteur No. 38, Bandung, Indonesia

e-mail: faridspine@gmail.com
}

fourth ventricle, sylvian fissure, cavernous sinus, sella, and temporal bone. . $^{4,6,7}$

\section{Case}

A 2 -year old boy admitted with a chief complaint of sudden decreased of consciousness. He was also presented with a tonic clonic seizure. NCCT examination revealed a well-defined extra-axial cystic mass located in the posterior fossa, $3.4 \times 3.9 \times 4.2 \mathrm{~cm}$ in size (Fig 1). Based on the NCCT image, the mass appear to be occupying the posterior fossa area and originating from the roof of the fourth ventricle. Gross examination presented cystic components and hard nodule features. Resection of the tumor was performed through the use of suboccipital craniotomy surgical technique. The mass was completely excised and sent for histopathological examination. The histopathological examination showed multiple cystic areas lined by the brain tissue admixed with islands of cartilage and salivary gland, elements and occasional intestinal type glands. 


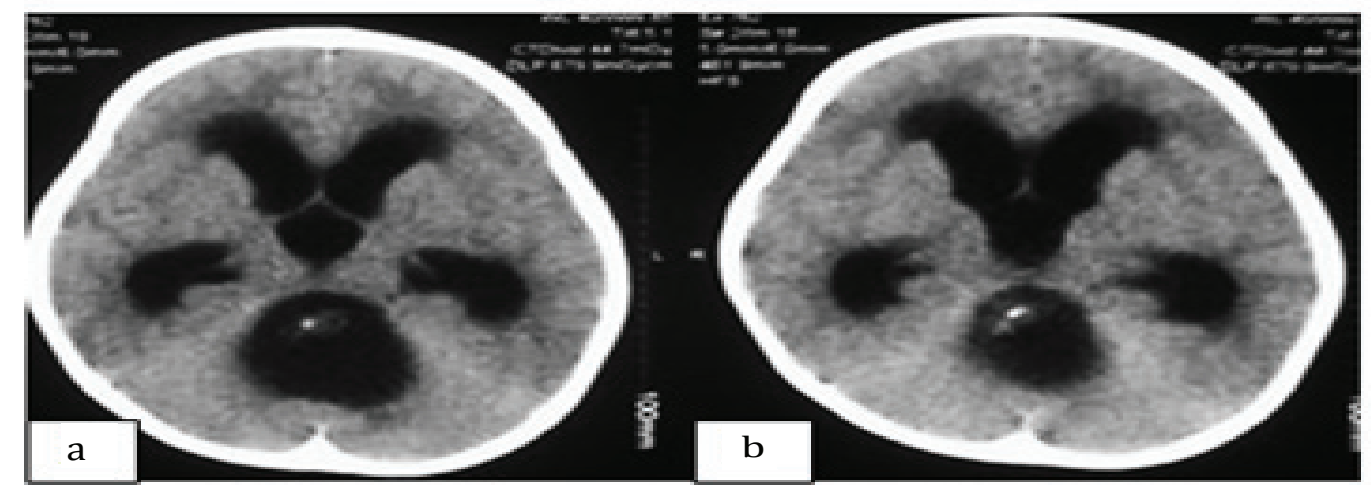

Fig. 1a Non-Contrast Head Computed Tomography Imaging Revealed Acute Hydrocephalus. 1b Non-Contrast Head Computed Tomography Imaging Showed a Cyst-like Mass and Non-homogenous Hyperintense of Posterior Fossa

The mass was covered with a whitishyellow membrane and located extraaxially. It was easily detached from the surrounding tissues of the brain and removed completely (Fig. 2a, b, c). During the process of debulking, gut-like structures were observed (Fig. 2d). Postoperatively, there was no neurological deficit observed. On gross examination, cystic component and hard nodule were revealed. The samples from excised tumor were fixed in $10 \%$ formalin, routinely processed and paraffin-embedded. Five $\mu \mathrm{m}$ sections were stained using the hematoxylin and eosin (HE) method. The entire specimen was submitted for histologic examination which revealed the presence of various fully differentiated tissue elements. Mesodermal derivatives (Fig. 3a, b) including adipose and fibrous connective tissues, cartilage, bone and striated muscle were abundant. Neuroectodermal components were represented by delicate fibrillar tissue, in which mature glial elements (mainly astroglia)

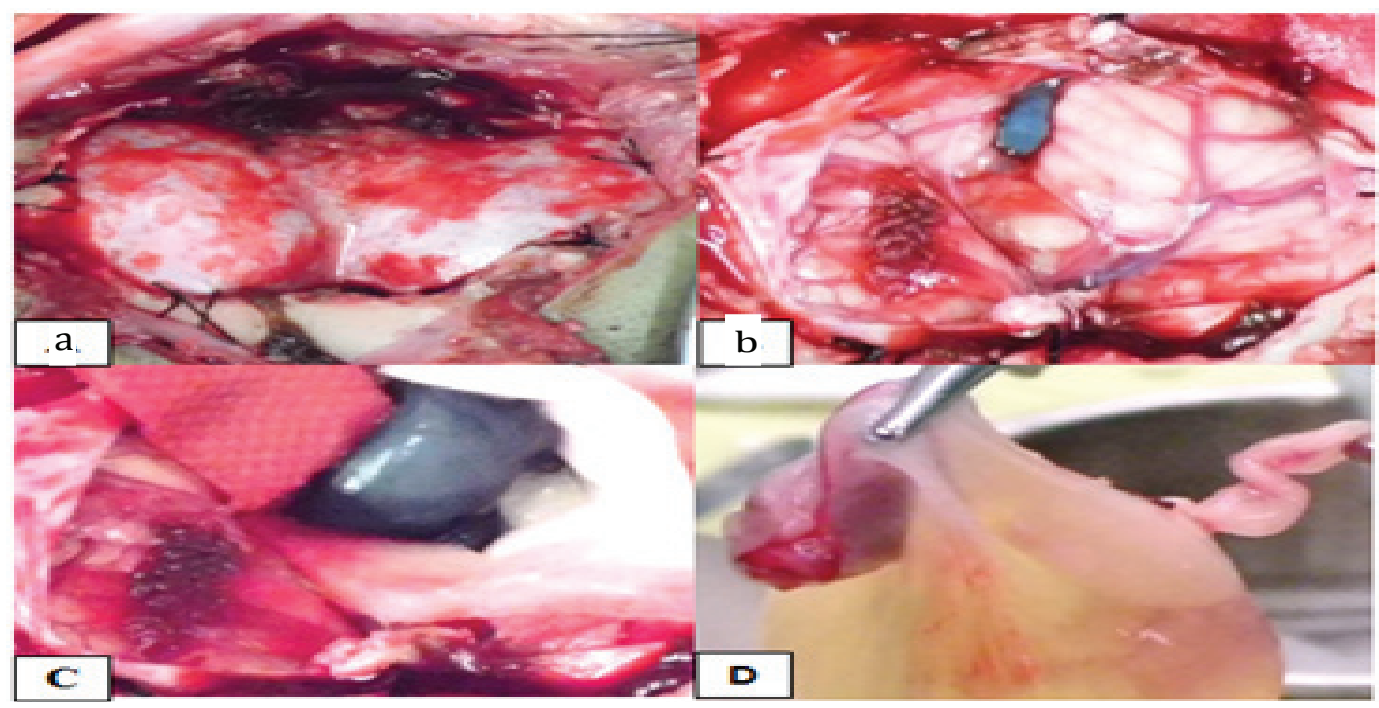

Fig. 2a, b Intraoperative Photographs. After Suboccipital Craniotomy and the Process of Debulking. 1c, The Mass was Easily Detached from the Surrounding Brain Parenchym. 1d, Tumor Mass Presented Gut-like Structure, Brain, and Amniotic Sac 


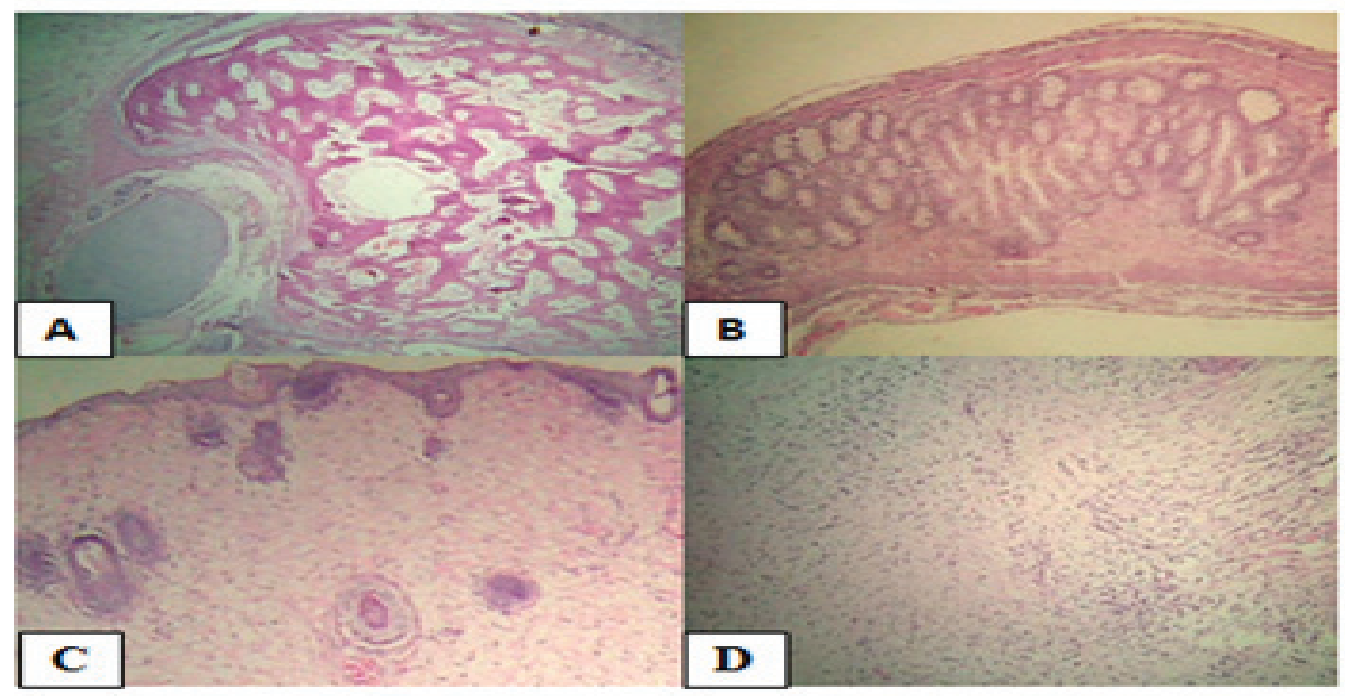

Fig. 3a, b Histopathology H\&E Stain 40x. Nodule of Moderately Cellular Cartilage, Connective Fibrous Tissue and Mature Fat Cells. 3c, d Neuroectodermal Components of Mature Teratoma, Hypocellular Fibrillar Tissue in which Glial Cells Predominate

predominated (Fig. 3c, d), but mature neuronal elements were also present. The tumor was moderately vascularized with predominantly smaller vessels and small foci probably injury took place during the operation. Mitotic figures were not present. The diagnosis of mature teratoma was established.

\section{Discussion}

Teratomas are nongerminomatous germ cell tumors differentiating into all three germ layers ectodermal derivatives in $100 \%$ of the tumors, mesodermal structures in 93\%, and endodermal derivatives in 71\% (which occurs in ovarian teratomas). The incidence intracranial teratomas $0.2 \%$ higher in children and the ration of male : female is 5:1. Mostly these tumor located are in the supratentorial midline and the pineal region. ${ }^{4,7}$

TheWorld Health Organizationclassification of intracranial teratoma delineates three histological variants: mature, immature and teratoma with malignant transformation. Mature teratomas are composed of fully differentiated tissue elements of the three germ cells and have a good prognosis with a reported 10-year survival rate of greater than $90 \%$. The prognosis for patients with immature teratoma is less favorable, with a 5-year survival rate of up to $70 \%$. The hallmark of immature teratomas is the presence of undifferentiated components exhibiting embryonal or fetal appearances. The immature component is frequently composed of neuroepithelial elements that can give rise to more malignant tumors. Teratomas with malignant transformation, containing a conventional malignant tumor of somatic type (i.e. sarcoma or carcinoma), are associated with poor prognosis. ${ }^{1,3,4}$

There were only a few cases of mature posterior fossa teratomas have been reported. Morelli from India published a radiographic report and Blackwell et al published the first report with histological examination. ${ }^{1}$ The largest study was reported by Noudel et al that revealed sellar or pineal region mature teratomas in 5 of 14 patients. The histological diagnosis is essential in managing intracranial teratomas to provide a definitive diagnosis and determine the choice of treatment. Histological examination revealed the presence of immature neural tissue (ectoderm), connective fibrous tissue, and 
mature fat cells and cartilage (mesodermal), salivary gland tissue (endodermal), as well as intestinal type glands adjacent to brain tissue in the tumor. Total removal of the tumor is thought to be the gold standard for treatment of mature teratoma and generally shows no recurrence. . $^{7,910}$

Early ultrasonography examination during the second or third trimester of pregnancy may indicate intracranial teratoma, heterogeneous mass with hyperechogenic mixed with hypoechogenic features which also associated with polyhydramnios and hydrocephalus. A study in 2007 reviewed of 39 cases with $10 \%$ were detected before 24 weeks of gestation

\section{References}

1. Kim JW, Park SS, Wang KC, Cho BK, Kim SY, Ra EK et al. Fetus-in-fetu in the cranium of a 4-monthold boy: histopathology and short tandem repeat polymorphism-based genotyping: Case report. J Neurosurg Pediatr. 2008;1(5):410-4.

2. Saada J, Delahaye S, Martinovic J, Macaleese J And Benachi A. Early second-trimester diagnosis of intracranial teratoma. Ultrasound Obstet Gynecol. 2009;33(1):109-11.

3. Khan Z, Watson WJ. Congenital intracranial teratoma prenatal diagnosis and vaginal delivery. J Ultrasound Med. 2010;29(7):11479.

4. Dimov I, Stojanović I, Stojanović S, Stojanović N, Stefanović I, Dimov D. Mature Intracranial Teratoma: Case report. Sci J Fac Med. 2013;30(2):97-102.

5. O'Grady J, Kobayter L, Kaliaperumal C, O'Sullivan M. 'Teeth in the brain'-a case of giant intracranial mature cystic teratoma. BMJ Case Rep. 2012; [cited 2015 Jan 10]:[about 4 p.]. and $44 \%$ were detected between 28 and 32 weeks of gestation. ${ }^{8}$ Early appearance can be observed in ultrasonograph during prenatal care and termination of pregnancy might be an option though but it is illegal in some of asian country. $2,3,8$ The patient underwent a total resection in April, 2012. During the follow-up period of one year, there was no evidence of tumor recurrence.

In summary, this is an unusual case of mature cyst teratoma especially for tumor located in the posterior fossa. Total surgical resection and long-term follow-up is the treatment of choice for mature teratoma.

Available from: http://www.ncbi.nlm.nih.gov/ pmc/articles/PMC3387452/.

6. Zhao J, Yu J, Zhong Y, Ge P. Cerebral Falx Mature Teratoma with Rare Imaging in an Adult. Int J Med Sci. 2012;9(4):269-73.

7. Sanyal P, Barui S, Mathur S, Basak U. A case of mature cystic teratoma arising from the fourth ventricle. Case reports in pathology. 2013; [cited 2015 Jan 10]:[about 3 p.]. Available from: http://www.ncbi.nlm.nih.gov/pmc/articles/ PMC3677652/.

8. Chan LW, Leung TN, Fung TY, Lau TK. Foetal intracranial teratoma: choosing the best time and mode of delivery. Hong Kong Med J. 2007;13(4):323-6.

9. Kharosekar UK, Jasmit S, Velho V, Palande DA: Congenital orbital teratoma up to posterior fossa. J Pediatr Neurosci. 2014;9(2):182-4.

10. Gao J, Zheng Z. Immature teratoma of the posterior cranial fossa in a 4-month-old infant: A case report. Oncol Letters. 2013;6(1):19-22. 